LICENÇA CC BY: Artigo distribuído sob os termos

Creative Commons, permite uso e distribuição irrestrita em qualquer meio desde que o autor credite a fonte original.

\section{VIVER PARA ESCREVER: SARTRE COMO FILÓSOFO-EDUCADOR}

\author{
LIVING TO WRITE: SARTRE AS A PHILOSOPHER-EDUCATOR \\ VIVIENDO PARA ESCRIBIR: SARTRE COMO FILÓSOFO-EDUCADOR
}

Maurício Silva ${ }^{1}$

1Programa de Pós-Graduação em Educação, Universidade Nove de Julho, São Paulo, SP, Brasil.

Artigo recebido em: 01/04/2020

Aprovado em: 20/10/2020

Resumo: Este artigo tem como objetivo discutir alguns aspectos da filosofia sartriana que revelem uma intersecção entre sua filosofia (e também sua biografia) e o que se pode chamar, muito genericamente, de processo educacional, isto é, fatos e fenômenos que apresentam, de modo direto ou indireto, um lastro pedagógico mais ou menos evidente em sua produção filosófica. Do ponto de vista metodológico, realizamos uma pesquisa bibliográfica, buscando a interação entre filosofia e educação, tendo como resultado parcial da referida pesquisa a ideia do ato pedagógico como um ato libertário, numa linhagem de pensamento capaz de aproximar Sartre e Paulo Freire.

Palavras-chave: Educação; Sartre; Processo educacional; Existencialismo.

Abstract: This article discuss some aspects of Sartrean philosophy that reveal an intersection between his philosophy (and also his biography) and what could be called, very generically, the educational process, that is, facts and phenomena that present, whether directly or indirectly, a pedagogical backing that is evident in his philosophical production. In terms of methodology, we conducted a literature review on the interaction between philosophy and education. The partial result of this research is the idea of the pedagogical act as a libertarian act, in a line of thought capable of approaching Sartre and Paulo Freire.

Key words: Education; Sartre; Educational process; Existentialism.

Resumen: Este artículo tiene como objetivo discutir algunos aspectos de la filosofía sartriana que revelan una intersección entre su filosofía (y también su biografía) y lo que se puede llamar, muy genéricamente, el proceso educativo, es decir, los hechos y fenómenos que se presentan, de manera directa. o indirectamente, un lastre pedagógico más o menos evidente en su producción filosófica. Desde un punto de vista metodológico, realizamos una búsqueda bibliográfica, realizando la interacción entre filosofía y educación, con el seguiente resultado parcial de la investigación: la idea del acto pedagógico como un acto libertario, en un linaje de pensamiento capaz de acercar a Sartre y Paulo Freire.

Palabras clave: Educación; Sartre; Proceso educativo; El existencialismo. 


\section{Introdução}

"Sartre vivait pour écrire". Com essa afirmação, Simone de Beauvoir (1960, p. 17), a eterna companheira de Sartre, relembrava os primeiros encontros com o filósofo francês. A importância dessa asserção, contudo, vai além da evidência de uma primeira impressão causada por Sartre naqueles que o rodeavam - ela revela, principalmente, um modo de ver o mundo, mais de uma vez confessado pelo próprio filósofo, que pode ser resumido como uma adesão incondicional à palavra escrita. Por isso, da mesma maneira que foi um leitor assíduo, Sartre foi também escritor voraz, escrevendo diariamente, motivo pelo qual nos deixou uma obra tão vasta. Ainda em 1926, dez anos antes da publicação de seu primeiro livro, numa carta escrita para Simone Jolivet (com quem teve um relacionamento que se estendeu por três anos), Sartre (1983) confessava: "J'ai écrit mon primier roman à 8 ans. Je ne peut pas voir une feuille de papier blanc sans avoir envie d'écrire quelque chose dessus" (p. 9). Para Sartre, com efeito, escrever (e sua contrapartida, o ato da leitura) era a maneira como sabia interpretar a realidade, razão de ter feito da escrita uma arma de luta e resistência ao longo de toda a vida.

Não podemos negar que essa cultura grafocêntrica, à qual Sartre adere deliberadamente desde sua infância - como, aliás, confessa em seu autobiográfico e sugestivamente intitulado livro Les mots (1964), dividido em duas grandes partes: lire e ecrire -, tenha relação direta com o que poderíamos chamar, provisoriamente, de processo educacional. De fato, embora mais filósofo do que educador, Sartre esteve, desde o início, direta ou indiretamente envolvido com processos educacionais diversos, seja como aluno, seja como professor, seja ainda como alguém cujas palavras - lidas e escritas - tinham muito a ensinar.

Diferentemente de muitos filósofos, para quem a educação fora motivo de profundas reflexões e, às vezes, até mesmo alguns títulos, em Sartre esse tema só aparece marginalmente, no sentido de que, embora não tenha produzido nenhum texto exclusivamente dedicado ao assunto, o vivenciou na prática de seu cotidiano social e intelectual. Por isso mesmo, podemos dizer, ao nos referirmos a sua figura, tratar-se de um filósofo-educador (mais do que um educador-filósofo), em cuja filosofia a educação parece readquirir seu sentido etimológico de "condução para fora" (ex-ducere), como a sugerir, a um só tempo, o ato e o processo de transportar alguém para fora de si mesmo, o que não é pouco para um filósofo que fez da oposição entre o em-si e o para-si a base de sua ontologia (LEOPOLDO E SILVA, 2013).

O objetivo deste artigo não é, portanto, discutir a fundo os aspectos da filosofia sartriana que possam, eventualmente, contribuir para uma teoria da educação, uma vez que, como vimos há pouco, seu pensamento revela-se um tanto refratário a uma tarefa dessa envergadura, mas apontar aspectos que revelem uma intersecção entre sua filosofia (e também sua biografia) e o que aqui chamamos muito genericamente de processo educacional, isto é, fatos e fenômenos que apresentam, de modo direto ou indireto, um lastro pedagógico mais ou menos evidente.

Para tanto, dividiremos nossas considerações entre três abordagens distintas, mas complementares, de sua vida e obra: uma abordagem biográfica, em que se ressalta sua 
atuação como aluno e como professor; uma abordagem filosófica, em que se discute(m) a(s) possibilidade(s) de empregar sua filosofia como fundamento da educação; e uma abordagem pragmática, em que se trata de algum tema caro ao seu pensamento que, como sugerimos antes, tenha algo a nos ensinar.

\section{Um filósofo-educador}

O processo educativo em Sartre pressupõe a consideração de uma abordagem biográfica, em que se destaca sua atuação como aluno e como professor, devendo-se, portanto, tratar, em primeiro lugar, do processo educativo de Sartre.

Com efeito, Sartre esteve boa parte de sua vida diretamente vinculado a uma educação formal: primeiro, na condição de aluno - tendo recebido as primeiras instruções de seu avô (Charles Schweitzer), passou, posteriormente, por várias escolas (Lycée de La Rochelle, Lycée Henri-V, Lycée Louis-le-Grand, École Normale Supérieure), rapidamente evoluindo para estudos mais profundos, indo, inclusive, estudar na Alemanha; depois, na condição de professor começa a ensinar em 1931, como substituto de um professor no Liceu François I (em La Havre), e passando, em 1937, a lecionar no tradicional Liceu Pasteur (em Neuilly) e, mais tarde, no Liceu Condorcet. Embora tenha abandonado a docência em 1944, pode-se dizer que Sartre, desde o início, manteve-se "attaché à um enseignement fondé sur la formation de l'esprit critique" (NOUDELMANN, 2004, p. 159).

Sua relação com a escola, contudo, tanto numa quanto noutra condição, parece ter sido sempre conturbada. Em La Rochelle (1917), por exemplo, após o segundo casamento de sua mãe, Sartre vive uma vida um tanto contraditória: amante dos livros e prodígio em algumas matérias, estuda entre alunos provenientes, na sua maioria, de famílias rurais ou pequenoburguesas, pouco afeitas à leitura. Como professor de filosofia em La Havre (1931), outro exemplo, revela-se um assumido inconformado, fazendo depois circular por aquele lugar Roquentin, herói de seu primeiro grande sucesso literário: A náusea (RICHARDIN, 2005). Apesar disso, viveu um período bastante aprazível como aluno da célebre École Normale Supérieure (1924), onde convive com nomes como os de Merleau-Ponty (de quem foi amigo) e Raymond Aron (que se tornaria seu desafeto); é ali também que conheceria Simone de Beauvoir, de quem se tornaria amigo e companheiro (CONTAT, 2005).

De qualquer maneira, o magistério o desgostava bastante, como ele mesmo afirma, já no final da vida, em Sartre par lui-même (1976), célebre documentário sobre sua carreira, em que confessaria o incômodo com fatos como o curso tradicional, as aulas expositivas, etc. A par disso, desagradava-lhe, em especial, a ideia de que, no magistério, havia um "domínio de disciplina e ordem". Assim, como instituição formal de ensino, tanto a universidade quanto o liceu pareciam não satisfazer o espírito impetuoso, dinâmico e, de certo modo, iconoclasta daquele que se tornaria um dos principais filósofos do Ocidente. Não custa lembrar que, ainda no início de sua juventude, Sartre (1983) escreveria outra 
carta a Simone Jolivet, em que afirmaria expressamente: "I'école est particulièrement triste en ce moment (...) Je viens de passar une suite des examens (...) et je ne fais plus que rester abruti à ma table de travail" (p. 12).

Tratar da relação de Sartre com a educação requer, ainda, o que chamamos de uma abordagem filosófica, em que se considera o potencial de sua filosofia como fundamento da educação. Essa é, certamente, uma das questões mais complexas no trato dessa relação, uma vez que, entre outras coisas, instala-se, logo de início, uma grande controvérsia: poderia a filosofia sartriana oferecer subsídios epistemológicos - e, mais do que isso, ontológicos - para o campo da educação?

Certamente, alguns pesquisadores responderiam negativamente a essa pergunta, mas, de modo geral, parece não haver dúvida de que, se sua filosofia não pode ser considerada um sistema regularmente voltado para o universo da educação, pode, sem dúvida, oferecer subsídios teóricos e conceituais para que ela possa ser pensada de modo mais amplo.

Bonnie Burstow (2000), da Universidade de Toronto, parece ter sido quem melhor sintetizou essa questão em seu conhecido artigo "Sartre: a possible foundation for educational theory?", publicado originalmente no Journal of Philosophy of Education. Para a professora canadense, a noção sartriana de facticidade (aquilo que é, dizendo respeito a resistências e objetos com os quais a liberdade necessariamente se defronta e aos quais reage) torna possível relacionar sua filosofia diretamente ao campo educacional, no sentido de se conceber, dentro desse universo, o que Sartre considera o ser-para-outros. Dessa forma, afirma a autora, Sartre defende uma educação intrinsecamente ligada às necessidades do indivíduo, lembrando que sua filosofia é especialmente relevante para a educação das crianças, já que

uma boa base na filosofia sartriana poderia possibilitar que o educador dê às crianças a assistência de que precisam para tratar de maneira positiva os dilemas existenciais com os quais necessariamente se defrontarão. (p. 124).

Na base desse pensamento encontra-se, il va sans dire, a noção sartriana de liberdade, no sentido de que ela serviria, de modo geral, como fundamento para a educação: uma educação para a liberdade - inclusive no sentido freiriano que esse conceito sugere (MOREIRA \& ROSA, 2014) - e uma educação para a responsabilidade, em sua correlação/interação com o Outro (SILVA, 2005).

Liberdade e responsabilidade sempre estiveram na raiz da filosofia sartriana - e, por extensão, do próprio existencialismo -, e parece ser esse o caminho que melhor se vislumbra quando falamos na possibilidade de empregá-las como fundamento da educação. Para Sartre (1996), com efeito, o homem situa-se no mundo por meio de seus atos (actes), sendo, na verdade, nada mais do que seu projeto (projet), um devir, existindo apenas na medida em que ele o realiza ("I'homme est d'abord ce qui se jette vers un avenir, et ce qui est conscient de se projeter dans l'avenir", p. 30). Nesse sentido, considerando então que a existência precede a essência, o homem passa a ser responsável por aquilo que é - o existencialismo coloca sobre o próprio homem a responsabilidade total de sua existência, não no sentido de que é 
responsável pela sua individualidade, mas no de que é responsável por todos os homens.

Advém daí essa ideia de responsabilidade por si mesmo e pelos outros, que subsidia - como vimos em alguns teóricos - o "projeto" educacional sartreano. Mas nada disso se sustenta se não estiver vinculado à noção primária em Sartre de liberdade:

a liberdade não é uma propriedade que pertença entre outras coisas à essência do ser humano (...) A liberdade humana precede a existência do homem e torna-a possível: a essência do ser humano acha-se em suspenso na liberdade. (SARTRE, 2014, p. 68).

Como lembra Walter Lima (2009) ao relacionar a noção de revolta em Sartre e sua produtividade no universo da educação,

uma prática educativa, que prime pela formação de uma práxis individual autônoma e livre, só existe ao preço de uma revolta, por uma educação-revolta e por um indivíduo historicamente situado e, sendo assim, por uma atividade educativa e pedagógica que busca a realização da liberdade como condição de humanização do homem. (p. 10).

Finalmente, é possível pensar a relação entre Sartre e a educação a partir de uma abordagem pragmática, no sentido de se verificar, por assim dizer na prática, o que a filosofia sartriana pode nos oferecer como conhecimento. Não estamos interessados, nesta abordagem, na ideia própria da filosofia sartriana de que todos nós possuímos um conhecimento interiorizado, que não depende de um processo de aprendizagem (SARTRE, 2015), mas, antes, no que sua filosofia pode representar em termos, mais propriamente, de ensinamento. Peguemos, para essa perspectiva, um dos muitos temas tratados por Sartre ao longo de sua extensão produção filosófica: a literatura.

Como sabemos, Sartre foi, além de um filósofo reconhecido pela profundidade de seu pensamento, um admirado escritor de ficção, entre romances, contos e peças de teatro que nos legou. Mas foi também, como que unindo ambas as perspectivas (filosófica e literária), um exímio crítico literário, resultado não apenas daquele incondicional apego à leitura literária - a que nos referimos no início deste artigo -, mas também de uma apaixonada atividade como comentarista e crítico de textos de literatura. Camus, Genet, Flaubert, Kafka, Baudelaire... são apenas alguns dos muitos nomes que povoaram suas reflexões e seus escritos.

Como crítico de literatura, revela-nos uma instigante face de filósofo-educador, no sentido mais plano - mas não menos importante - de que nos apresenta caminhos, estratégias, conceitos e métodos de leitura do texto ficcional. Original em suas proposições acerca desse tema, Sartre "inaugura" uma crítica que, segundo Frederic Jameson (2005), reside na maneira como ele trata o estilo literário como fenômeno objetivo, mais do que subjetivo, além de conceber a obra literária como uma construção mental voltada para a criação de um efeito:

contrairement à ceux pour qui l'oeuvre d'art est l'occasion privilégiée d'établir un contact avec une forme plus profonde, avec l'inconscient, la personalitée, avec l'Être, ou le langage, Sartre se situe parmi les rhétoriciens. L'oeuvre d'art est une construction mentale conçue pour produire un certain effet. (p. 126).

Um de seus melhores textos, nesse sentido, é o célebre Qu'est-ce que la littérature?, publicado parcialmente na revista Les Temps modernes (1947) e, posteriormente, no volume Situations I/ (1948). Nesta obra, Sartre (1989) parte da definição da literatura como um ato de 
liberdade, passando pela valorização do leitor e pela importância da leitura como razão de ser da literatura, até atingir, por fim, aquilo que ele considera como sendo a função social da arte literária. Com efeito, durante toda a obra, Sartre procura enxergar a literatura como prática da liberdade, uma liberdade conquistada e atuante, que representa a definição mesma da própria literatura. Assim, enquanto que na abordagem concreta da literatura o filósofo francês vê uma evolução histórica do escritor (para ele, o escritor do século XVII fazia parte da elite e o do século XVIII passa a se situar entre a elite e a burguesia ascendente), em sua consideração conceitual, Sartre enxerga a arte como uma categoria que "tem o seu fundamento na liberdade do autor e constitui um apelo à liberdade do leitor" (p. 120). Além disso, julga a literatura um apelo "à liberdade dos homens para que realizem e mantenham o reino da liberdade humana" (p. 75).

Outra ideia de Sartre, proposta neste seu texto, diz respeito à relação que o leitor e o ato da leitura estabelecem com a literatura propriamente dita. Na verdade, para Sartre, a literatura só encontra sua razão de ser no ato supremo da leitura, sem a qual toda obra esvazia-se de significação e importância. Assim, pode-se dizer que, a rigor, só há obra literária na presença do leitor. Aliás, o próprio ato da leitura é uma ato criador, em que o leitor assume sua parcela de responsabilidade criativa:

uma vez que a criação só pode encontrar sua realização final na leitura, uma vez que o artista deve confiar a outrem a tarefa de completar aquilo que iniciou, uma vez que é só através da consciência do leitor que ele pode perceber-se como essencial à sua obra, toda obra literária é um apelo. (p. 39).

Analisando, numa perspectiva histórica, o conceito de literatura engajada, Benoît Denis (2002) considera que Sartre representa o apogeu da literatura engajada. De fato, mais do que qualquer outro tema, é a noção de engajamento que o filósofo procura desenvolver neste seu Que é Literatura? Para Sartre, há, em toda estética, um imperativo moral, responsável pelo engajamento do escritor; mais do que isso, esse engajamento provém do fato de que escrever é um ato de liberdade, motivo pelo qual faz necessário haver um engajamento completo do escritor em sua criação, de forma ativa e indubitável. Nessa visão de engajamento, há um inter-relacionamento entre algumas ideias centrais na crítica sartriana, como a de literatura e sociedade, segundo a qual a liberdade reivindicada pela literatura só seria possível numa democracia, e a essência plena do ato literário encontra sua razão numa sociedade sem classes. Neste sentido, não seria difícil perceber que o autor procura tirar a literatura do âmbito do "prazer" e colocá-la no âmbito da "missão" - em vez de atividade contemplativa, a criação literária passa a ser um ofício:

escrever não é viver, nem tampouco afastar-se da vida para contemplar, num mundo em repouso, as essências platônicas e o arquétipo de beleza, nem deixar-se lacerar como se se tratasse de espadas, por palavras desconhecidas, incompreendidas, vindas detrás de nós: é escrever um ofício. Um ofício que exige um aprendizado, um trabalho continuado, consciência profissional e senso de responsabilidade. (SARTRE, 1989, p. 171).

Com efeito, para Sartre, escrever é despertar nos homens não só a vontade, mas a necessidade da prática: é necessário, portanto, que cada palavra traga dentro de si uma mensagem clara e concreta, um significado real, explícito, sem o que a literatura perderia em muito a sua essência. 
Essa concepção de literatura nasce, em parte, da ideia que Sartre tem da literatura como produto de uma sociedade histórica e como uma instituição burguesa, apresentando uma visão da literatura como instituição, em oposição a uma perspectiva idealista da atividade literária (DUBOIS, 1979). De fato, como afirma Albérès (1964), seu livro Que é Literatura? "rejette la littérature poétique, artistique et métaphysique, em faveur d'une prose destinée à une action morale, sociale et politique" (p. 100). E essa é uma contribuição - quase dizíamos um "ensinamento" - incontestável da filosofia sartriana para a teoria literária de todas as épocas.

\section{Considerações finais}

Vimos que a relação de Sartre com a educação apresenta a complexidade que ambos os elementos dessa equação, por si sós, possuem: de uma lado, a filosofia sartriana, com todos os seus princípios, conceitos e métodos; de outro lado, o imponderável mundo da educação, com seus infinitos desdobramentos, teóricos ou práticos.

Em nosso estudo, que não teve, em momento algum, a ambição de ser nem profundo, nem extenso, analisamos essa relação sob uma tripla perspectiva: uma abordagem biográfica, uma abordagem filosófica e uma abordagem pragmática. Em todas elas, a figura de Sartre destaca-se como um pensador polêmico, instigante, profundo e sedutor. Se não se dispôs a escrever diretamente sobre a educação, o fez indiretamente, na medida em que refletiu sobre a essência e a existência de cada um, sobre o ser e sobre o nada, sobre a liberdade e sobre a angústia de existir, sobre a solidão e sobre o inacabamento do ser humano. Tudo isso diz, na sua essência, à educação...

Em sua célebre narrativa intitulada Le mur (O muro), de 1939, Sartre narra a angústia do prisioneiro Pablo Ibbieta à espera da execução, que deverá vir no dia seguinte. Nesta narrativa, uma das ideias centrais é a de que a vida deve ser compreendida diante de seu duplo, a morte - é precisamente nesse sentido que se pode compreender a vida humana como algo inacabado, incompleto: "ma vie - dizia o protoganista do conto - était devant moi, close, fermée, comme um sac, et pourtant tout ce qu'il y avait dedans était inachevé" (SARTRE, 2016, p. 27). Esse sentido de inacabamento do ser humano traz em si a tese freiriana do homem como um ser inconcluso: como Sartre, Paulo Freire também acreditava que a liberdade é, na verdade, uma conquista, exigindo uma permanente busca, num movimento dialético em que estão inscritos os homens como seres inconclusos (FREIRE, 2010). Por isso, completa Freire (2009), ensinar exige consciência do inacabamento do ser humano: "é na inconclusão do ser, que se sabe como tal, que se funda a educação como processo permanente" (p. 58).

Filósofo-educador malgré lui, Sartre, com certeza, tinha plena consciência de que alcançar a liberdade fazia parte de um movimento que não dispensava - pelo contrário, pressupunha e até mesmo exigia - a adoção de um ato pedagógico incontornável. 


\section{Referências}

ALBÉRÈS, R.-M. Jean-Paul Sartre. Paris: Éditions Universitaire, 1964.

BEAUVOIR, Simone de. La force de I’âge. Paris: Gallimard, 1960.

BURSTOW, Bonnie. A filosofia sartriana como fundamento da educação. Educação \& Sociedade, Centro de Estudos Educação e Sociedade - Cedes, Ano XXI, No. 70: 103-126, abr. 2000.

CONTAT, Michel. Sartre: L’invention de la liberté. Paris: Les Éditions Textuel.2005.

JAMESON, Frederic. Les trois méthodes de la critique littéraire sartrienne. In: CONTAT, Michel (Org.). Sartre. Paris: Bayard, 2005, p. 126-151.

DENIS, Benoît. Literatura e engajamento: de Pascal a Sartre. Bauru: Edusc, 2002.

DUBOIS, Jacques. Vers une théorie de l'institution. In: DUCHET, Claude et alii. Sociocritique. Paris: Nathan, 1979, p. 159-171.

FREIRE, Paulo. Pedagogia da Autonomia. Saberes Necessários à Prática Educativa. São Paulo: Paz e Terra, 2009.

Pedagogia do Oprimido. Rio de Janeiro: Paz e Terra, 2010.

LEOPOLDO E SILVA, Franklin. Sartre e o Humanismo. São Paulo: Barcarola/Discurso Editoral, 2013.

LIMA, Walter Matias. Algumas considerações sobre educação em Jean-Paul Sartre. Revista Tempos e Espaços em Educação, São Cristóvão: Universidade Federal de Sergipe, Vol. 3: 9-22, jul.-dez. 2009.

MOREIRA, Janine \& ROSA, Marisa de S. Thiago. Jean-Paul Sartre e Paulo Freire: aproximações entre a liberdade existencialista e a educação libertadora. Revista Contrapontos - Eletrônica, Itajaí: Programa de Pós-Graduação em Educação da UNIVALI, Vol. 14, No. 3: 407-424, set.-dez. 2014.

NOUDELMANN, François; PHILIPPE, Gilles. Dictionaire Sartre. Paris: Honoré Champion, 2004.

RICHARDIN, Sophie. Les mille visages de Sartre. Boulogne: Timée-Éditions, 2005.

Sartre par lui-même. Dir. Alexandre Astruc, 1976, 187m.

SARTRE, Jean-Paul. Les mots. Paris: Gallimard, 1964.

Lettres ao Castor et à quelques autres (1926-1939). Ed. par Simone de Beauvoir. Paris: Gallimard, 1983.

Que é Literatura? São Paulo: Ática, 1989.

. L'existentialisme est un humanisme. Paris: Gallimard, 1996.

O ser e o nada. Ensaio de ontologia fenomenológica. Petrópolis: Vozes, 2014.

O que é a subjetividade. Rio de Janeiro: Nova Fronteira, 2015. 
. Le mur. Paris: Gallimard, 2016.

SILVA, Luciano Donizetti da. Existencialismo e educação - a filosofia sartriana da liberdade como fundamento pedagógico. Aprender - Caderno de Filosofia e Psicologia da Educação, Vitória da Conquista, Ano III, No. 4: 175-200, 2005. 